\title{
Prevention of disability on grounds of suffering
}

S D Edwards University of Wales Swansea, Swansea

\begin{abstract}
This paper examines one particular justification for the screening and termination of embryos/fetuses which possess genetic features known to cause disability. The particular case is that put forward in several places by fohn Harris. He argues that the obligation to prevent needless suffering justifies the prevention of the births of disabled neonates. The paper begins by rehearsing Harris's case. Then, drawing upon claims advanced in a recent paper in the fournal of Medical Ethics, it is subjected to critical scrutiny, focusing on Harris's "suffering claim" (the claim that a life with disability inevitably involves suffering on a significant scale). ${ }^{1}$ It is argued that the suffering claim must be false if understood as an empirical claim. And, even if understood as a conceptual truth, it mistakenly assimilates the concepts of harm and suffering. Finally, again focusing on Harris's recent work in this area, his characterisation of disability as a "harmed condition" is shown not to apply in the case of at least some moderate forms of intellectual disability.

(Fournal of Medical Ethics 2001;27:380-382)
\end{abstract}

Keywords: John Harris; disability; prevention of disability on grounds of suffering.

A common justification for the human genome project is that it will help reduce the incidence of disability. Once it has been established that a genetic abnormality responsible for a disability is present in an embryo/fetus, the birth of a neonate with such a disability can be prevented, either by termination or by gene therapy. The main reason given for seeking to prevent the births of disabled neonates is that in preventing such births one is preventing suffering, and the prevention of suffering is morally desirable.

An influential proponent of such a line of argument is Professor John Harris. ${ }^{1-3}$ It is his view that one does wrong if one intentionally brings a child with a disability into the world. The wrong done in such cases is that of "deliberately choosing to increase the suffering in the world when [one] could have avoided so doing". In giving birth to a disabled child one is responsible for the infliction of "needless suffering".
Moreover, it is Harris's view that one can be responsible for a moral wrong by an omission (by "negative actions"). ${ }^{6}$ Hence, one will be morally culpable if, given grounds to suspect that one might conceive a disabled fetus, one does not seek screening after conception and terminate the pregnancy if disability is discovered. (As he writes "it can also be wrong not to terminate a pregnancy". $)^{4}$

There is one important exceptional class of cases in which Harris allows that one might be justified in intentionally giving birth to a disabled child. This exception concerns cases in which, for some reason, it is impossible for the mother to conceive non-disabled children. In such cases, he states, it is "better to have children with disabilities than no children at all". ${ }^{4}$ So if it is impossible for one to give birth to healthy children, then giving birth to a disabled child is preferable to having no children.

The allowance of this exception is interesting since, strictly speaking, it might be thought that the obligation to prevent needless suffering would lead to the conclusion that it is a moral wrong to give birth to any children. For human lives typically involve at least some suffering. This is so even if the lives of most of us involve more pleasure than suffering.

But Harris takes the desire to have children to be a very strong one which should be respected. ${ }^{4}$ Presumably on the grounds that the advantages which accrue from the satisfaction of this desire outweigh the disagreeable consequence that some suffering will result from it. Thus the obligation to prevent suffering is not taken to lead to the conclusion that it is a moral wrong to give birth to any children. The weight attached to the importance of respecting the desire to have children is greater than that attached to the obligation to prevent suffering.

Given that, overall, one does not act wrongly in having healthy children if one can, Harris's position assumes a distinction between suffering which is unavoidable, and suffering which is needless. In giving birth to healthy children in the knowledge that their lives are likely to involve some suffering, one's actions lead to unavoidable suffering. But in giving birth to a disabled child, when one could have prevented its birth, one's actions lead to 
avoidable, needless suffering and are therefore morally wrong (ie in that they transgress moral obligations not to cause needless suffering-either by one's actions or by one's omissions). It is worth adding that in Harris's view a disabled person "will inevitably suffer". ${ }^{7}$

An example he discusses involves parents who, in the process of undergoing in vitro fertilisation (IVF) treatment, choose to implant an embryo which has a genetic abnormality known to cause deafness when they could have chosen to have a healthy embryo implanted. ${ }^{8}$ In making such a choice they are causing inevitable and needless suffering.

So if it is accepted that there is a general obligation not to do wrong by causing needless suffering, there is an obligation not to give birth to disabled neonates, to terminate them (painlessly). And also, there is an obligation to seek screening if one has grounds to suppose that one is likely to conceive an embryo with a genetic disorder known to cause disability.

The implications of this position are so drastic that it is worth pausing to spell some of them out. To reiterate, the position is as follows. With respect to any genetic condition known to cause disability the following applies. If such a condition is detected in an embryo/fetus; and if it is possible for the mother to conceive a healthy embryo at a later time; then it is a moral wrong to continue with the pregnancy and give birth to a disabled neonate. Moreover, since one can do a moral wrong by an omission one will be morally culpable if, given grounds to suspect that one might conceive a disabled fetus, one does not seek screening after conception, and terminate the pregnancy if disability is discovered. (This is of course subject to the proviso noted above, ie that it is possible for one to conceive a healthy child at a later date.)

So consider a specific disability, that of Down's syndrome. Those people who, once informed that their fetus has the abnormality which causes Down's syndrome, do not terminate the pregnancy do a moral wrong. And those who have grounds to suspect they may give birth to a Down's syndrome child ought to seek a test to determine whether the embryo has this abnormality and then terminate the pregnancy should such an abnormality be found.

The position which Harris develops lends considerable support to the Human Genome Project (HGP). Given acceptance of the claim that there is a necessary relationship between disability and suffering; and given that the HGP can help us to identify genetically caused disabilities; then the HGP can indeed be viewed as a morally praiseworthy project. A major aim of it being the identification of genetic abnormalities which cause disabilities.

Having set out Harris's position I turn now to examine it more critically. As noted, Harris places great weight on the view that in causing needless suffering one does a moral wrong. Having healthy children, in the knowledge that they are very likely to experience some suffering, is fine. But having disabled children is a wrong.

As noted, such a view seems to rely on a distinction between the levels of suffering which typically befall most people and the level of suffering which a disabled person can expect to endure. He takes suffering to be an inescapable accompaniment of disability; and to be of a magnitude significantly greater than that which can be expected in the life of a non-disabled person.

Let us describe the following "suffering claim".

The suffering claim. A life with a disability inevitably involves suffering, or harm of some significant level.

"Significant" can be taken to mean a degree of harm or suffering above that which might reasonably be expected to befall a typical healthy person during their lifetime.

On the face of it the claim seems vulnerable to objection. If the suffering claim is treated as an empirical claim all that is required to falsify it is the provision of a credible example of a person with a disability leading a happy, fulfilling life. (Recall that Harris posits a relationship of necessity between disability and suffering. $)^{7}$ On the assumption that if a person leads a happy life then they cannot be said to be suffering, it seems to me that at least one counter-example to Harris's suffering claim could be found. ${ }^{9}$ In fact I suspect that several counterexamples could be found, for example of people with moderate intellectual disabilities. It seems perfectly plausible to suppose that many such people lead lives with no more suffering than is endured by a typical non-disabled person.

Moreover, it is plausible to suppose that significant numbers of moderately intellectually disabled people living in Western countries live lives with very considerably less degrees of suffering than non-disabled people in many poorer parts of the world. Hence, if understood as an empirical claim, the suffering claim must be false. The relationship between disability and suffering is not necessary, as Harris maintains, ${ }^{5}$ but is contingent. The presence of disability in a person is not a sufficient condition for the life of that person being beset with suffering. And given the kind of lives endured by many nondisabled people in very poor countries it is plain that there are causes of suffering other than disability. The relationship between disability and suffering is one of neither necessity nor sufficiency.

In a recent paper Harris elaborates on the sense in which disability is a harm. He states that he favours a "harmed condition" 10 model of disability. This helps to fill out the sense in which, for Harris, there is a relationship of necessity between disability and suffering. For by definition, if $\mathrm{x}$ is disabled $\mathrm{x}$ is in a harmed state, and reasonably enough, $x$ might be said to be suffering. This now makes the suffering claim sound more like a conceptual truth rather than an empirical claim.

But there is a serious weakness in this position. Harm and suffering may be related but they differ importantly. The difference can be described in the 
following way. A person can be harmed without actually undergoing unpleasant or undesirable mental experiences at the time they are harmed. For example, a married couple may be out enjoying themselves in a restaurant whilst, unknown to them, a burglar is ransacking their home. It is plausible to claim they are being harmed during the time of the burglary even though they do not, at the time of the burglary, feel as though they are being harmed. It is not plausible, however, to claim they are suffering during the time of the burglary; though of course when they return home and see what has been done to their home they may then endure the experience of suffering.

This example points up the difference between harm and suffering. For it to be true that a person is suffering it is necessary that the person undergoes the kind of mentally distressing feelings which are a necessary condition of the presence of suffering. ${ }^{11}$ No such experience is required for it to be true that a person is being harmed.

Let us now return to the question of the rightness or wrongness of giving birth to disabled neonates. The justification given in Harris's position for preventing such births is that in doing so one is inevitably reducing the incidence of suffering. As suggested above this is deeply implausible since, for example, many people with moderate intellectual disabilities lead happy lives, with no more suffering than is endured by non-disabled people. And as seen, in characterising disability as a harmed condition, it still does not follow that people with disabilities are suffering, even if it is accepted that they are harmed by their condition. For suffering requires the experience of suffering; so leading a life in a harmed condition does not entail that one is suffering, or enduring more suffering than is typically endured by non-disabled people.

I think what has been claimed so far goes some considerable way to call into question the main justification Harris offers for his position on the bring ing into being of disabled neonates. But in the space remaining I'd like to go further and query his characterisation of disability as a harmed condition.

In the recent paper Harris discusses the example of deafness. The harm that this brings is "the deprivation of worthwhile experience". ${ }^{12}$ A dimension of experience available to hearing people is not available to deaf people. It may be said in response to this that being deaf similarly is a dimension of human experience not available to hearing people. But let this pass. The idea that disability deprives people of an important dimension of human experience works least problematically in relation to sensory disabilities such as deafness. But how does it apply to people with moderate intellectual disability and no accompanying sensory disabilities? I suppose it may be said that a moderately intellectually disabled person misses out on those dimensions of experience which require considerable intellectual acumen, for example doing complex work in physics, maths or even philosophy. But of course it may be said of those of average intelligence that they too miss out on such experiences. And it may be said of those without musical ability that they miss out on that dimension of human experience; and so on. The point is it does not follow from the fact that one is constitutionally incapable of experiencing certain aspects of human experience that one is either suffering or in a harmed condition.

In conclusion: the main purpose of this paper has been to look closely at the claim that it is right to prevent the births of people with disabilities because it is right to prevent needless suffering. I considered the case for such a position as it is set out by John Harris. But if the analysis presented above is correct, the case is flawed and some other ground of justification is required.

S D Edwards, BA(hons), MPhil, PhD, is Senior Lecturer in Philosophy of Health Care, the Centre for Philosophy and Health Care, University of Wales Swansea, Swansea.

\section{References}

1 Harris J. Is there a coherent social conception of disability? fournal of Medical Ethics 2000;26:95-100

2 Harris J. Clones, genes and immortality. Oxford: Oxford University Press, 1998.

3 Harris J. Wonderwoman and Superman. Oxford: Oxford University Press, 1992

4 See reference 2: 91

5 See reference 2: 88 .

6 Harris J. Violence and responsibility. London: Routledge \& Kegan Paul, 1980: 24.

7 See reference 2: 88, 89.

9 Stainton T, Besser H. The positive impact of children with an intellectual disability on the family fournal of Intellectual $\mathcal{E}$ Developmental Disability 1998;23:57-70; Ferguson PM, Gartner A, Lipsky DK. The experience of disability in families: a A, Lipsky DK. The experience of disability in families: a synthesis of research and parent narratives. In: Parens E, Asch A, eds. Prenatal testing and disability right

10 Seorgetown University

1 Cassell $\mathrm{E}$. The nature of suffering and the goals of medicine. Oxford: Oxford University Press, 1991.

12 See reference 1: 98. 